Original Research Article

\title{
Role of clopidogrel in addition to aspirin in the prevention of recurrent ischaemic events in acute coronary syndrome with ST-segment elevation
}

\author{
Vasavi Patra $^{1 *}$, Victor Emmanuel Ulchala ${ }^{2}$
}

${ }^{1}$ Department of Pharmacology, ${ }^{2}$ Department of General Medicine, Spark Hospitals, Peerzadiguda, Uppal, Hyderabad, Telangana, India

Received: 10 July 2018 Accepted: 16 July 2018

*Correspondence to:

Dr. Vasavi Patra,

Email: vasavipatra@yahoo.in

Copyright: (C) the author(s), publisher and licensee Medip Academy. This is an openaccess article distributed under the terms of the Creative Commons Attribution NonCommercial License, which permits unrestricted noncommercial use, distribution, and reproduction in any medium, provided the original work is properly cited.

\begin{abstract}
Background: Studies regarding the efficacy of Aspirin alone versus combination of Aspirin and Clopidogrel in patients with Unstable Angina are many. But, studies on the comparative role of Aspirin alone versus Aspirin plus Clopidogrel in the background of Acute Coronary Syndrome (ACS) with ST segment elevation myocardial infarction (STEMI) were very few, at the time of starting of this study. Keeping this in mind present study was conducted to compare the efficacy and safety of Aspirin alone with combination of aspirin plus Clopidogrel in prevention of events in Acute Coronary Syndrome with ST segment elevation myocardial infarction.
\end{abstract}

Methods: Patients who are admitted to intensive coronary care unit within $12 \mathrm{hrs}$ after the onset of symptoms and whose diagnosis as ACS with ST segment elevation has been established were included in this study. Patients in group 1 received $325 \mathrm{mg}$ of aspirin as loading dose, followed by $150 \mathrm{mg}$ once daily. Patients in group 2 received a combination of aspirin and Clopidogrel 325 and $300 \mathrm{mg}$, respectively, as loading dose, followed by $150 \mathrm{mg}$ of aspirin and $75 \mathrm{mg}$ of Clopidogrel daily. All the patients received a fibrinolytic agent. Treatment response was weighed against the primary and secondary expected outcomes.

Results: Addition of Clopidogrel to Aspirin resulted in significant reduction in severe ischaemia not requiring urgent revascularisation i.e.; 32\% in Aspirin alone group versus 10\% in Aspirin plus Clopidogrel group and recurrent angina with no ECG changes i.e.; $42 \%$ in aspirin alone group versus 20\% in Aspirin plus Clopidogrel group. Similarly, there was an improvement in ejection fraction at the end of one month i.e.; $0.3 \%$ in Aspirin alone group versus 1.85\% in Aspirin plus Clopidogrel group.

Conclusions: This study demonstrates the benefit of adding Clopidogrel to Aspirin for myocardial infarction with ST-segment elevation. Treatment with a loading dose of $300 \mathrm{mg}$ of Clopidogrel followed by a daily dose of $75 \mathrm{mg}$, in addition to aspirin, resulted in significant improvement in the secondary efficacy related outcomes in patients with acute coronary syndrome with ST-segment elevation.

Keywords: Acute coronary syndrome, Aspirin, Clopidogrel, ST-segment elevation myocardial infarction

\section{INTRODUCTION}

The term Acute Coronary Syndrome (ACS) is given to a heterogenous group of clinical entities encompassing Unstable Angina (UA), non ST-segment elevation myocardial infarction (NSTEMI), and ST-segment elevation myocardial infarction (STEMI). The underlying mechanism of ACS is the ruptured or eroded atherosclerotic plaque leading to thrombus formation. ${ }^{1}$

The mortality rate with acute infarction is approximately $30 \%$, with more than half of these deaths occurring before 
the stricken individual reaches the hospital. Although the mortality rate after admission for myocardial infarction has declined by about $30 \%$ over the last two decades, approximately 1 of every 25 patients dies in the first year, of initial hospitalization, after myocardial infarction. A substantial proportion of patients mainly those receiving fibrinolytic therapy only for myocardial infarction with ST-segment elevation have inadequate reperfusion or reocclusion of the infarct-related artery, leading to an increased risk of complications and death.

Aspirin and heparin have been shown to reduce the risk of death from cardiovascular causes, new myocardial infarction and recurrent ischemia., ${ }^{2,3}$ But continuous treatment with heparin or LMWH beyond one week has not been shown to be effective. Intravenous GlycoproteinIIb/IIIa receptor blockers have been shown to reduce the incidents of early events, but long term use of oral Gp-IIb /IIIa receptor blockers may increase the mortality. Also, no convincing evidence of benefit is yet available after long term use of oral anticoagulants. Therefore, there is a need for new agent which can be used for reduction of recurrent events following ACS.

The thienopyridine derivatives, Ticlopidine and Clopidogrel, are antiplatelet agents that inhibit the platelet aggregation induced by adenosine diphosphate, thereby reducing the ischemic events. ${ }^{4}$ Combining one of these drugs with Aspirin, which blocks the thromoxane mediated pathway, may have an additive effect.

Clopidogrel has been tested vis-à-vis Aspirin for its role in prevention of thrombotic events in patients at high risk of ischaemic events in CAPRIE trial. Similarly, in CURE study, Clopidogel plus Aspirin has been compared with Aspirin alone in patients with Unstable angina. But there was dearth of studies on comparative role of Aspirin alone and Aspirin plus Clopidogrel in the background of ACS with ST-segment elevation, when this study was conducted.

Thus, this study has been designed to show the efficacy and safety of Aspirin alone in comparison to a combination of Aspirin and Clopidogrel in prevention of recurrent ischaemic events in ACS with ST-segment elevation.

\section{Stemi}

Patients with ischaemic chest pain lasting >20 minutes, ECG shows ST segment elevation of $1 \mathrm{~mm}$ or more in two or more contiguous leads or new onset LBBB. Elevation of cardiac enzymes (of two or more times of upper limit of normal range) and/ or a positive troponin test.

\section{Nstemi}

Patients with ischaemic chest pain, elevation of cardiac enzymes and/ or marker as in STEMI but without ECG criteria of STEMI.

\section{Unstable angina}

Patients who fulfill one of the following criteria:

- Rest pain lasting >20 minutes

- New onset angina (2 months) that is severe and/ or frequent (3episodes per day)

- Crescendo angina

\section{Death from cardiovascular causes}

It is defined as any death for which there was no clearly documented non-vascular cause.

\section{Stroke}

It is defined as a new focal neurologic deficit of vascular origin lasting more than 24 hour.

\section{Refractory ischaemia in the hospital}

It is defined as recurrent chest pain lasting more than 5 minutes with new ischaemic ECG changes while the patient is receiving optimal medical therapy, and which lead to additional interventions (such as thrombolytic therapy, cardiac catheterization, insertion of intra aortic balloon pump, coronary revascularisation) by mid night of the next calender day.

\section{Refractory ischaemia after discharge}

That is defined by rehospitalization lasting at least 24 hours for unstable angina, with ischaemic ECG changes.

\section{Severe sichaemia (in the hospital)}

It is defined as ischaemia that is similar to in-hospital refractory ischaemia but for which no urgent intervention is performed.

\section{Recurrent angina (in the hospital)}

It is defined similarly, but ECG changes are not required.

\section{Major bleeding episodes}

They are defined as substantially disabling bleeding, intra ocular bleeding leading to loss of vision, or bleeding necessitating transfusion of at least 2 units of blood.

Major bleeding will be classified as life threatening if the bleeding episode is fatal or leads to reduction in the haemoglobin of at least $5 \mathrm{~g} / \mathrm{dL}$ or to substantial hypotension requiring the use of intravenous ionotropic agents, if it necesitates a surgical intervention, if it's a symptomatic intracranial haemorrhage, or if it necessitates the transfusion of 4 or more units of blood. 


\section{Minor bleeding episodes}

It include other hemorrhages that lead to the interruption of the study medication.

Aims and objectives was to evaluate the efficacy and safety of Aspirin alone in comparison to a combination of Aspirin and Clopidogrel in prevention of events in ACS with ST- segment elevation.

\section{METHODS}

This is a randomized, open label, controlled clinical study, conducted at Lisie Medical Institutions, Kerala from February 2004 to February 2005 and followed the Good Clinical Practice guidelines (ICH).

\section{Study design}

The patients of ACS with ST-segment elevation were randomised and divided in to two groups each comprising of 50 patients in number. Patients in group 1 received $325 \mathrm{mg}$ of Aspirin as loading dose, followed by $150 \mathrm{mg}$ once daily. Patients in group 2 received a combination of Aspirin and Clopidogrel $325 \mathrm{mg}$ and $300 \mathrm{mg}$ respectively as loading dose, followed by $150 \mathrm{mg}$ of Aspirin and $75 \mathrm{mg}$ of Clopidogrel daily. All the patients received a fibrinolytic agent.

Coronary angiography was performed, in those who could afford for it, during the index hospitalization 48 to 72 hours after the start of study medication, to assess for the late patency of the infarct related artery. Angiography was performed before $48 \mathrm{hrs}$ had elapsed only if clinically indicated. For patients who underwent coronary stenting, it was recommended that open label Clopidogrel be administered, with the use of a loading dose of at least $300 \mathrm{mg}$, followed by a daily dose of $75 \mathrm{mg}$. Other necessary medications were administered with intention to treat.

Composite end points were analysed at the time of discharge, at one and three months, and then every 3 months till the end of the study (which was for a period of 6 months). Telephone follow up of 12 patients who lost to follow up was performed to identify clinical end points or adverse events.

\section{Study patients}

Patients who were admitted to intensive coronary care unit were included in this study. Only those patients of less than 75years of age, who were hospitalised within 12 hours after the onset of symptoms and whose diagnosis as ACS with ST- segment elevation has been established by clinical features, ECG findings and evaluation of enzymes, were included in this study (as laid in the guidelines for evaluation of acute chest pain by ACC/AHA and NCEP).

Patient with contraindications to antithrombotic or antiplatelet therapy, those at high risk for bleeding or severe heart failure, those who were taking oral anticoagulants and those who had undergone coronary revascularisation in the previous three months or had received intravenous $\mathrm{Gp}$-IIb/IIIa receptor inhibitors in the previous three days were excluded from this study.

\section{Treatment response}

Treatment response was weighed against the following expected outcomes. The first primary expected outcome was the composite of death from cardiovascular causes, refractory ischaemia and stroke. The secondary expected outcomes were severe ischaemia, recurrent angina and an improvement in ejection fraction at the end of one month. The safety related expected outcomes were that of bleeding complications.

\section{RESULTS}

The observations were analysed by chi square test to know the level of significance. $\mathrm{P}$ value $<0.05$ is considered to be significant.

Table 1: Baseline characteristics of the patients.

\begin{tabular}{|lll|}
\hline Characteristics & $\begin{array}{l}\text { Aspirin alone } \\
\text { group (AA) } \\
\text { 50 patients }\end{array}$ & $\begin{array}{l}\text { Aspirin plus } \\
\text { Clopidogrel group } \\
\text { (AC) 50 patients }\end{array}$ \\
\hline Age in years & 56.5 & 58.9 \\
\hline Male sex & $45(90 \%)$ & $39(78 \%)$ \\
\hline $\begin{array}{l}\text { Diabetes } \\
\text { mellitus }\end{array}$ & $22(44 \%)$ & $14(28 \%)$ \\
\hline Hypertension & $19(38 \%)$ & $15(30 \%)$ \\
\hline Dyslipidaemia & $48(96 \%)$ & $46(90 \%)$ \\
\hline Smoking & $35(70 \%)$ & $22(44 \%)$ \\
\hline $\begin{array}{l}\text { Peripheral } \\
\text { vascular disease }\end{array}$ & $2(4 \%)$ & $2(4 \%)$ \\
\hline $\begin{array}{l}\text { Prior } \\
\text { myocardial } \\
\text { infarction }\end{array}$ & $8(16 \%)$ & $10(20 \%)$ \\
\hline $\begin{array}{l}\text { Prior } \\
\text { Cerebrovascular } \\
\text { accidents }\end{array}$ & $3(6 \%)$ & $0(0 \%)$ \\
\hline
\end{tabular}

The average age of Aspirin alone group was 56.5 years and that of Aspirin plus Clopidogrel group was 58.9 years. There were more males in Aspirin alone group (90\%) compared to Aspirin plus Clopidogrel group (78\%). Likewise, diabetics (44\% in Aspirin alone vs. $28 \%$ in Aspirin plus Clopidogrel group) and smokers (70\% in Aspirin alone group versus $44 \%$ in Aspirin plus Clopidogrel group) were more in Aspirin alone group. There was no significant difference with regard to the proportion of hypertensives (38\% in Aspirin alone group vs. $30 \%$ in Aspirin plus Clopidogrel group), patients with dyslipidaemia (96\% in Aspirin alone group versus 90\% in Aspirin plus Clopidogrel group), peripheral vascular disease (4\% in each group), and prior myocardial infarction (16\% in Aspirin alone group vs. 20\% in Aspirin 
plus Clopidogrel group). 6\% of Aspirin alone group had prior history of cerebro vascular accident while none in Aspirin plus Clopidogrel group had such a history in Table 1.

\section{Efficacy end points}

The primary efficacy end points in this study were the composite of death from cardiovascular causes, refractory ischaemia necessitating an urgent revascularisation and stroke. The secondary efficacy end points were severe ischaemia not requiring urgent revascularisation, recurrent angina with no ECG changes and an improvement in ejection fraction at the end of one month. The safety related expected outcomes were that of bleeding complications.

Addition of Clopidogrel to Aspirin did not result in any significant difference in primary end points i.e.; death due to cardiovascular causes (16\% in Aspirin alone group versus $6 \%$ in Aspirin plus Clopidogrel group; $p$ value0.2011 ), refractory ischaemia necessitating an urgent revascularization (10\% in Aspirin alone group vs $12 \%$ in Aspirin plus Clopidogrel group; $\mathrm{p}$ value-0.7493), need for revascularization (26\% in Aspirin alone group versus 20\% in Aspirin plus Clopidogrel group; $p$ value-0.6346) and stroke (4\% in each; $p$ value-1.0) (Table 2).

Table 2: Primary efficacy end points.

\begin{tabular}{|llll|}
\hline $\begin{array}{l}\text { Primary } \\
\text { efficacy end } \\
\text { points }\end{array}$ & $\begin{array}{l}\text { Aspirin } \\
\text { alone } \\
\text { group } \\
\text { (AA) }(50 \\
\text { patients) }\end{array}$ & $\begin{array}{l}\text { Aspirin plus } \\
\text { Clopidogrel } \\
\text { group (AC) } \\
(\mathbf{5 0} \text { patients) }\end{array}$ & $\begin{array}{l}\text { p - } \\
\text { value }\end{array}$ \\
\hline $\begin{array}{l}\text { Death from CV } \\
\text { causes }\end{array}$ & $8(16 \%)$ & $3(6 \%)$ & 0.2011 \\
\hline $\begin{array}{l}\text { Refractory } \\
\text { ischaemia } \\
\text { requiring urgent } \\
\text { revascularisation }\end{array}$ & $5(10 \%)$ & $6(12 \%)$ & 0.7493 \\
\hline $\begin{array}{l}\text { Stroke } \\
\text { Need for }\end{array}$ & $2(4 \%)$ & $2(4 \%)$ & 1.0 \\
\hline revascularisation & $13(26 \%)$ & $10(20 \%)$ & 0.6464 \\
\hline
\end{tabular}

However, there was a significant difference in some of the secondary efficacy related end points. Addition of Clopidogrel to Aspirin resulted in a significant reduction in severe ischaemia not requiring urgent revascularization (from $32 \%$ to $10 \%$; p value-0.0141), and recurrent angina with no ECG changes (from $42 \%$ to $20 \%$; p value-0.0306). Similarly, there was an improvement in ejection fraction at the end of one month from $0.3 \%$ to $1.8 \%$ (Table 3 ).

Addition of Clopidogrel to Aspirin resulted in no significant increase in the risk of major bleeding $(2 \%$ in each group; $p$ value - 1.0). Similarly, the risk of minor bleeding was not significantly more with the addition of Clopidogrel to Aspirin (6\% in Aspirin plus Clopidogrel group versus $4 \%$ in the group which received Aspirin alone; $p$ value - 0.6464) (Table 4).

Table 3: Secondary efficacy end points.

\begin{tabular}{|lll|l|}
\hline $\begin{array}{l}\text { Secondary } \\
\text { efficacy end } \\
\text { points }\end{array}$ & $\begin{array}{l}\text { Aspirin } \\
\text { alone } \\
\text { group } \\
\text { (AA) } \\
\text { patients) }\end{array}$ & $\begin{array}{l}\text { Aspirin plus } \\
\text { Clopidogrel } \\
\text { group (AC) } \\
\text { (50 patients) }\end{array}$ & $\begin{array}{l}\text { p - } \\
\text { value }\end{array}$ \\
\hline $\begin{array}{l}\text { Severe } \\
\text { ischaemia not } \\
\text { requiring urgent } \\
\text { revascularisation }\end{array}$ & $16(32 \%)$ & $5(10 \%)$ & 0.0141 \\
\hline $\begin{array}{l}\text { Recurrent } \\
\text { angina with no } \\
\text { ECG changes }\end{array}$ & $21(42 \%)$ & $10(20 \%)$ & 0.0306 \\
\hline $\begin{array}{l}\text { Improvement of } \\
\text { ejection fraction } \\
\text { at the end of one } \\
\text { month }\end{array}$ & $0.3 \%$ & $1.8 \%$ & 0.031 \\
\hline
\end{tabular}

Table 4: Safety end points.

\begin{tabular}{|llll|}
\hline $\begin{array}{l}\text { Safety } \\
\text { related out } \\
\text { comes }\end{array}$ & $\begin{array}{l}\text { Aspirin } \\
\text { alone group } \\
\text { (AA) (50 } \\
\text { patients) }\end{array}$ & $\begin{array}{l}\text { Aspirin plus } \\
\text { Clopidogrel } \\
\text { group (AC) } \\
\text { (50 patients) }\end{array}$ & $\begin{array}{l}\text { p - } \\
\text { value }\end{array}$ \\
\hline $\begin{array}{l}\text { Major } \\
\text { bleeding } \\
\text { episodes }\end{array}$ & $1(2 \%)$ & $1(2 \%)$ & 1.0 \\
\hline $\begin{array}{l}\text { Minor } \\
\text { bleeding } \\
\text { episodes }\end{array}$ & $2(4 \%)$ & $3(6 \%)$ & 0.6464 \\
\hline
\end{tabular}

\section{DISCUSSION}

Many studies like CAPRIE trial have shown the efficacy of Clopidogrel in prevention of thrombotic events in patients at high risk of ischaemic events. ${ }^{5}$ Similarly in CURE study, Clopidogel plus Aspirin has been compared with Aspirin alone in patients with Unstable angina. ${ }^{6}$ There were very few trials evaluating the efficacy of Clopidogrel in addition to Aspirin in patients with STEMI.

In this study a total of 100 patients underwent randomization having risk factors like age, sex, diabetes, hypertension, smoking, prior MI, dyslipidemia etc.

Addition of Clopidogrel to Aspirin did not result in any significant difference in primary end points i.e.; death due to cardiovascular causes ( $\mathrm{p}$ value-0.2011), refractory ischaemia necessitating an urgent revascularisation ( $p$ value-0.7493) and stroke ( $\mathrm{p}$ value-1.0).

However, there was a significant difference in some of the secondary efficacy related end points. Addition of Clopidogrel to Aspirin resulted in a significant reduction in severe ischaemia not requiring urgent revascularisation 
( $p$ value-0.0141) and recurrent angina with no ECG changes ( $p$ value-0.0306). Similarly, there was an improvement in ejection fraction at the end of one month $(0.3 \%$ in Aspirin alone group versus $1.85 \%$ in Aspirin plus Clopidogrel group).

The role of Clopidogrel in addition to Aspirin must be considered in the context of the form of reperfusion therapy (primary PCI, thrombolysis, or no reperfusion).

There are no randomized trials evaluating the efficacy of Clopidogrel in addition to Aspirin in patients with a STEMI who are treated with primary PCI. However, most clinicians give Clopidogrel based upon extrapolation from randomized trials (PCI-CURE and CREDO) in patients with a non-ST elevation ACS. These trials showed that Clopidogrel improves both short-term and long-term cardiovascular outcomes when given in addition to Aspirin in patients treated with PCI. ${ }^{6,7}$

The benefit from thrombolytic therapy in patients with STEMI is limited by the failure to achieve normal (TIMI grade III) flow in 40 to 50 percent of infarct-related arteries. In addition, threatened reocclusion occurs in 5 to 15 percent of cases. ${ }^{8-10}$

There are no randomized trials that specifically evaluated the efficacy of Clopidogrel in addition to Aspirin in patients with a STEMI who are not reperfused. However, one-half of patients in COMMIT/CCS-2, which demonstrated benefit from Clopidogrel therapy, were not reperfused. ${ }^{9}$ Most physicians also extrapolate from the benefit seen with Clopidogrel in patients with a non-ST elevation ACS who were not revascularized in the CURE trial. $^{11}$

As in other studies, in this study also it was noted that addition of Clopidogrel to aspirin did not result in any significant difference in primary end points i.e., death due to cardiovascular causes, refractory ischaemia necessitating an urgent revascularisation and stroke. However, there was a significant difference in the secondary efficacy related end points. Addition of clopidogrel to aspirin resulted in a significant reduction in severe ischaemia not requiring urgent revascularisation and recurrent angina with no ECG changes. Similarly there was an improvement in ejection fraction at the end of one month.

\section{CONCLUSION}

A substantial proportion of patients receiving fibrinolytic therapy for myocardial infarction with ST-segment elevation have inadequate reperfusion or re-occlusion of the infarct related artery leading to an increased risk of complications and death. Arterial thrombi that are rich in platelets are relatively resistant to fibrinolysis and are prone to induce re-occlusion after initial reperfusion. Despite the inhibition of cyclo-oxygenase by aspirin, platelet activation can still occur through thrombaxane-A2 independent pathways, leading to aggregation of platelets in the formation of thrombin. Clopidogrel is a potent antiplatelet agent that has a synergistic antithrombotic effect when combined with Aspirin. The beneficial effect of adding Clopidogrel to Aspirin has been proved beyond doubt in patients of unstable angina. When this study was started, there were very few randomised trials to prove the role of Clopidogrel in myocardial infarction with STsegment elevation.

This study demonstrates the benefit of adding Clopidogrel to Aspirin for myocardial infarction with ST-segment elevation. Treatment with a loading dose of $300 \mathrm{mg}$ of Clopidogrel followed by a daily dose of $75 \mathrm{mg}$, in addition to Aspirin, resulted in significant improvement in the secondary efficacy related out comes (severe ischaemia, recurrent angina and ejection fraction) in patients with acute coronary syndrome with ST-segment elevation. However, there was no significant improvement in the primary efficacy related end points (composite end point of death from cardiovascular causes, refractory ischaemia and stroke) with the addition of Clopidogrel at the end of six months. Treatment with Aspirin plus Clopidogrel was not associated with an increased rate of major bleeding.

\section{ACKNOWLEDGEMENTS}

Authors would like to thank Dr. Joseph Kurian, MD, Former Head of the Department, General Medicine, Dr. Rony Mathew, DM, HOD of Cardiology, Lisie Hospital, Cochin, Kerala, India.

Funding: No funding sources

Conflict of interest: None declared

Ethical approval: The study was approved by the Institutional Ethics Committee

\section{REFERENCES}

1. Myocardial infarction redefined-a consensus document of The Joint European Society of Cardiology/American College of Cardiology Committee for the redefinition of myocardial infarction. J Am Coll Cardiol. 2000;36:959.

2. Patrono C. Aspirin as an antiplatelet drug. N Engl J Med. 1994;330:1287.

3. Maalej N, Folts JD. Increased shear stress overcomes the antithrombotic platelet inhibitory effect of aspirin in stenosed dog coronary arteries. Circulation. 1996;93:1201.

4. Foster CJ, Prosser DM, Agans JM, Zhai Y, Smith MD, Lachowicz JE, et al. Molecular identification and characterization of the platelet ADP receptor targeted by thienopyridine antithrombotic drugs. J Clin Invest. 2001 Jun 15;107(12):1591-8.

5. Cannon, CP. Effectiveness of clopidogrel versus aspirin in preventing acute myocardial infarction in patients with symptomatic atherothrombosis (CAPRIE trial). Am J Cardiol. 2002;90:760. 
6. Mehta SR, Yusuf S, Peters RJ, Bertrand ME, Lewis BS, Natarajan MK, et al. Effects of pretreatment with clopidogrel and aspirin followed by long-term therapy in patients undergoing percutaneous coronary intervention: the PCI-CURE study. The Lancet. 2001 Aug 18;358(9281):527-33.

7. Steinhubl SR, Berger PB, Mann III JT, Fry ET, DeLago A, Wilmer C, et al. Credo Investigators. Early and sustained dual oral antiplatelet therapy following percutaneous coronary intervention: a randomized controlled trial. Jama. 2002 Nov 20;288(19):2411-20.

8. Sabatine MS, Cannon CP, Gibson CM, López-Sendón JL, Montalescot G, Theroux P, et al. Addition of clopidogrel to aspirin and fibrinolytic therapy for myocardial infarction with ST-segment elevation. New England J Med. 2005 Mar 24;352(12):1179-89.

9. Clopidogrel and Metoprolol in Myocardial Infarction Trial. Available at: http://www.commit-ces2.org. Accessed 24 March 2005.
10. Sabatine MS, Cannon CP, Gibson CM, López-Sendón JL, Montalescot G, Theroux P, et al. Effect of clopidogrel pretreatment before percutaneous coronary intervention in patients with ST-elevation myocardial infarction treated with fibrinolytics: the PCI-CLARITY study. JAMA. 2005 Sep 14;294(10):1224-32.

11. Yusuf, S, Zhao, F, Mehta, SR. Effects of clopidogrel in addition to aspirin in patients with acute coronary syndromes without ST-segment elevation. N Engl J Med. 2001 Aug 16;345(7):494-502.

Cite this article as: Patra V, Ulchala VE. Role of clopidogrel in addition to aspirin in the prevention of recurrent ischaemic events in acute coronary syndrome with ST-segment elevation. Int J Basic Clin Pharmacol 2018;7:1506-11. 